Calcium Carbonate Storage in Amorphous Form and Its

Template-Induced Crystallization

T. Y-J. Han, J. Aizenberg

March 7, 2008

Chemistry of Materials 
This document was prepared as an account of work sponsored by an agency of the United States government. Neither the United States government nor Lawrence Livermore National Security, LLC, nor any of their employees makes any warranty, expressed or implied, or assumes any legal liability or responsibility for the accuracy, completeness, or usefulness of any information, apparatus, product, or process disclosed, or represents that its use would not infringe privately owned rights. Reference herein to any specific commercial product, process, or service by trade name, trademark, manufacturer, or otherwise does not necessarily constitute or imply its endorsement, recommendation, or favoring by the United States government or Lawrence Livermore National Security, LLC. The views and opinions of authors expressed herein do not necessarily state or reflect those of the United States government or Lawrence Livermore National Security, LLC, and shall not be used for advertising or product endorsement purposes. 


\title{
Calcium Carbonate Storage in Amorphous Form and Its Template-Induced Crystallization
}

\author{
T. Yong-Jin Han ${ }^{* \dagger}$ and Joanna Aizenberg*, \\ $\dagger$ Chemistry and Materials Science Directorate, Chemistry and Chemical Engineering Division, \\ Lawrence Livermore National Laboratory, Livermore, CA 94551
}

\$ School of Engineering and Applied Sciences, Harvard University, 29 Oxford Street, Cambridge, MA 02138

* T.Y.-J. Han, han5@1lnl.gov; J. Aizenberg, jaizenberg@seas.harvard.edu

\begin{abstract}
Calcium carbonate crystallization in organisms often occurs through the transformation from the amorphous precursor. It is believed that the amorphous phase could be temporarily stabilized and stored, until its templated transition to the crystalline form is induced. Here we develop a bio-inspired crystallization strategy that is based on the above mechanism. Amorphous calcium carbonate (ACC) spherulitic particles are formed and stabilized on a self-assembled monolayer (SAM) of hydroxy-terminated alkanethiols on Au surface. The ACC is stored as a reservoir for ions and is induced to crystallize on command by introducing a secondary surface that is functionalized with carboxylic acid-terminated SAM. This secondary surface acts as a template for oriented and patterned nucleation. Various oriented crystalline arrays and micropatterned films are formed. We also show that the ACC phase can be doped with foreign ions (e.g. $\mathrm{Mg}$ ) and organic molecules (e.g. dyes) and that these dopants later function as growth modifiers of calcite crystals and become incorporated into the crystals during the transformation process of ACC to calcite. We believe that our strategy opens the way of using a stabilized amorphous phase as a versatile reservoir system that can be converted in a highly controlled fashion to a crystalline form upon contacting the nucleating template.
\end{abstract}

\section{INTRODUCTION}

The advancements in technology and science are often fueled by the development of new materials and by the discoveries of novel properties of existing materials, which can arise from the variations of their sizes, shapes, orientation, patterns and morphologies. This is especially true in the emerging field of nanotechnology, where shapes, sizes and orientation of materials are of critical importance and are crucial in determining their function. In an effort to control various parameters of inorganic materials synthesis, it is particularly fruitful to study how inorganic materials are formed in nature. Biology provides numerous examples of exquisite inorganic structures with functions including magnetic, optical and mechanical. ${ }^{1}$ Understanding the sophisticated, precise mechanisms with which biological molecules govern the synthesis of

\footnotetext{
${ }^{1}$ Lowenstam, H. A., Weiner, S. On Biomineralization, Oxford Univ. Press, Oxford 1989.
} 
inorganic materials in a bottom-up fashion can directly impact the nascent field of nanotechnology, where the controlled formation of materials is one of the essential components for its progress.

One example of biogenic inorganic materials with diverse micro/nanostructures and unique properties is calcium carbonate - the most abundant biomineral. The two major polymorphs of calcium carbonate, calcite and aragonite, have traditionally garnered the most attention. $^{2,3}$ Recently we have shown that amorphous calcium carbonate (ACC) might have multiple functions and importance in the biomineralization process. ${ }^{4,5}$ A number of studies addressing the structure ${ }^{6,7}$ and function of biogenic ACC followed. ${ }^{8,9}$ It has been demonstrated that a metastable ACC phase is often a transient precursor to the two dominant polymorphs, calcite $^{10,11}$ and aragonite ${ }^{12}$. Stable ACC is also formed by organisms and used as a skeletal material. ${ }^{4,13} 4$ above It has been proposed that ACC might participate in developing the final intricate microstructures of the biogenic crystalline calcium carbonates. ${ }^{14,15}$

The formation of synthetic spherulitic ACC stabilized by Mg ions that acted as transient precursor to a crystalline form of calcite was observed by Nancollas in $1976 .{ }^{16}$ Since then numerous studies of the synthesis of ACC in the metastable form and its subsequent conversion to crystalline calcium carbonates have been reported. ${ }^{17,18}$ The stabilization of ACC was commonly achieved by using various solution additives, including $\mathrm{Mg}^{17,19,20}$, biological macromolecules $^{4,13,21}$ and synthetic polymers. ${ }^{22,23,24}$ In particular, we have shown that hydroxyamino acid-rich macromolecules extracted from biogenic stable ACC induces the formation of a stable synthetic ACC phase. ${ }^{4,13}$ The formation of peptide-stabilized ACC that acts as a "liquid precursor phase" was reported by Gower et al. ${ }^{21,25,26}$ We have also shown that ACC can be surface-stabilized in the absence of additives when the precipitation of calcium carbonate

${ }^{2}$ Addadi, L., Weiner, S. Angew. Chem. Int. Ed., 1992, 31, 153.

${ }^{3}$ Davis, K. J., Dove, P. M., De Yoreo, J. J. Science 2000, 290, 1134.

${ }^{4}$ Aizenberg, J., Lambert, G., Addadi, L., Weiner, S. Adv. Mater., 1996, 8, 222.

${ }^{5}$ Beniash, E., Aizenberg, J., Addadi, L., Weiner, S. Proc. R. Soc. Lond. B, 1997, 264, 461.

${ }^{6}$ Hasse, B., Ehrenberg, H., Marxen, J. C., Becker, W., Epple, M. Chem. Eur. J., 2000, 6, 3679.

${ }^{7}$ Levi-Kalisman, Y., Raz, S., Weiner, S., Addadi, L., Sagi, I. Adv. Func. Mater., 2002, 12, 43.

${ }^{8}$ Addadi, L., Raz, S., Weiner, S. Adv. Mater., 2003, 15, 959.

${ }^{9}$ Meldrum, F. C. Int. Mater. Rev., 2003, 48, 187.

${ }^{10}$ Beniash, E., Addadi, L., Weiner, S. J. Struct. Biol., 1999, 125, 50.

${ }^{11}$ Politi, Y., Levi-Kalisman, Y., Raz, S., Wilt, F., Addadi, L., Weiner, S., Sagi, I. Adv. Func. Mater., $2006,16,1289$.

${ }^{12}$ Weiss, I. M., Tuross, N., Addadi, L., Weiner, S. J. Exp. Zool. B, 2002, 293, 478.

${ }^{13}$ Aizenberg, J., Lambert, G., Weiner, S., Addadi, L. J. Am. Chem. Soc., 2002, 124, 32.

${ }^{14}$ Aizenberg, J., Muller, D. A., Grazul, J. L., Hamann, D. R. Science, 2003, 299, 1205.

${ }^{15}$ Politi, Y., Arad, T., Klein, E., Weiner, S., Addadi, L. Science 2004, 306, 1161.

${ }^{16}$ Reddy, M. M., Nancollas, G. H. J. Cryst. Growth 1976, 35, 33.

${ }^{17}$ Raz, S., Weiner, S., Addadi, L. Adv. Mater., 2000, 12, 38.

${ }^{18}$ Faatz, M., Grohn, F., Wegner, G. Adv. Mater., 2004, 16, 996.

${ }^{19}$ Loste, E., Wilson, R. M., Seshadri, R., Meldrum, F. C. J. Cryst. Growth, 2003, 254, 206.

${ }^{20}$ Ajikumar, P. K., Wong, L. G., Subramanyam, G., Lakshminarayanan, R., Valiyaveettil, S. Cryst. Growth Des., 2005, 5, 1129.

${ }^{21}$ Gower, L. B., Odom, D. J. J. Cryst. Growth, 2000, 210, 719.

${ }^{22}$ Volkmer, D., Harms, M., Gower, L., Ziegler, A. Angew. Chem. Int. Ed., 2005, 44, 639.

${ }^{23}$ Donners, J. J. J. M., Heywood, B. R., Meijer, E. W., Nolte, R. J. M., Sommerdijk, N. A. J. M. Chem. Eur. J., 2002, 8, 2561.

${ }^{24}$ Xu, A.-W., Yiu, Q., Dong, W.-F., Antonietti, M., Cölfen, H. Adv. Mater., 2005, 17, 2217.

${ }^{25}$ Olszta, M. J., Gajjeraman, S., Kaufman, M., Gower, L. B. Chem. Mater, 2004, 16, 2355.

${ }^{26}$ Cheng, X. G., Gower, L. B. Biotechnol. Prog., 2006, 22, 141. 
occurs on a self-assembled monolayer (SAM) functionalized with biologically-relevant hydroxyl and phosphate groups. ${ }^{14}$ By introducing a 3D micropatterned environment and a single nucleation site on such a template, we have achieved the conversion of the ACC phase into a large, oriented, micropatterned single calcite crystal. Interesting examples of single micropatterned calcite crystals formed as a result of the amorphous-to-crystalline transition within a 3D template were reported by Meldrum et al. ${ }^{27,28}$

These studies have clearly shown that the ability to control the transition from an amorphous to a crystalline form emerges as a powerful biomimetic synthetic strategy that allows the fabrication of oriented and arbitrarily micropatterned crystalline materials. The difficulty arises from a high solubility of ACC and its spontaneous, uncontrolled recrystallization. ${ }^{29}$ Successful synthesis of stable ACC with or without additives will make it possible to store the material, manipulate the particles, study their structure, explore the transformation process and possibly understand its role in biomineralization. The function of amorphous phases as a storage for ions is believed to be a general biomineralization strategy. ${ }^{1}$ Here we describe a facile synthesis of stable ACC on a SAM template functionalized with hydroxyl groups. We show that ACC could be successfully stored in a dry atmosphere, and the crystallization could be triggered when needed by contacting a secondary template that bears calcite nucleating sites.

\section{MATERIALS AND METHODS}

Templates. Gold surfaces were prepared by E-beam evaporation of $50 \mathrm{~nm} \mathrm{Au}$ onto $\mathrm{Si}(100)$ wafer primed with $2 \mathrm{~nm} \mathrm{Ti}$ as adhesion promoter. Substrates were immediately submerged into a $5 \mathrm{mM}$ solution of a corresponding thiol in ethanol (for hydroxyl-terminated surfaces, HS- $(\mathrm{CH} 2)_{11}-\mathrm{OH}$ was used; for carboxylic acid-terminated surfaces, HS- $\left(\mathrm{CH}_{2}\right)_{15}-\mathrm{COOH}$ and $\mathrm{HS}-\left(\mathrm{CH}_{2}\right)_{10}-\mathrm{COOH}$ were used). The adsorption process of thiols to the metal substrate was allowed to take place for minimum of $6 \mathrm{hrs}$ at room temperature (RT). The resulting surfaces were rinsed with excess ethanol and dried under pressurized $\mathrm{N}_{2}$ flow. Microcontact printing was performed using published procedures. ${ }^{30,31}$

ACC precipitation. ACC was deposited by immersing the hydroxy-terminated template in $25 \mathrm{mM}$ solutions of $\mathrm{CaCl}_{2}$. The $\mathrm{ACC}$ formation took place inside a desiccator containing solid ammonium carbonate as the source of $\mathrm{CO}_{2}$ at $\mathrm{RT}$ for $30 \mathrm{~min}$ to $1 \mathrm{hrs}^{30,32}$ The resulting ACC on the templates was rinsed with acetone and dried under $\mathrm{N}_{2}$. The amorphous character of the precipitate was analyzed by X-ray diffraction (XRD) and IR spectroscopy. In several experiments, various dopants, such as $\mathrm{Mg}$ ions, dyes, proteins, peptides, were added to a $\mathrm{CaCl}_{2}$ solution prior to deposition. ${ }^{32,33}$

Crystallization. In order to induce recrystallization of ACC, carboxylic acidfunctionalized template was brought in direct contact with ACC. A small amount ( $\sim 1 \mathrm{ml})$ of water was placed in between the two substrates to initiate the recrystallization process. The

\footnotetext{
${ }^{27}$ Loste, E., Meldrum, F. C. Chem. Commun., 2001, 10, 901.

${ }^{28}$ Loste, E., Park, R. J., Warren, J., Meldrum, F. C. Adv. Func. Mater., 2004, 14, 1211.

${ }^{29}$ Lippmann, F. Sedimentary Carbonate Minerals, Springer-Verlag, Berlin, 1973.

${ }^{30}$ Aizenberg, J.; Black, A. J.; Whitesides, G. M. J. Am. Chem. Soc. 1999, 121, 4500.

${ }^{31}$ Love, J. C.; Estroff, L. A.; Kriebel, J. K.; Nuzzo, R. G.; Whitesides, G. M. Chem. Rev. 2005, $105,1103$.

${ }^{32}$ Albeck, S.; Aizenberg, J.; Addadi, L.; Weiner, S. J. Am. Chem. Soc. 1993, 115, 11691.

${ }^{33}$ Han, Y. J., Aizenberg, J. J. Am. Chem. Soc., 2003, 125, 4032.
} 
presence of ACC and recrystallized calcite crystals were confirmed by optical and scanning electron microscopy (SEM). The orientations of the crystals were determined by XRD and morphological analysis. ${ }^{30}$

\section{RESULTS AND DISCUSSION}

We have shown previously that SAMs of hydroxyl-terminated alkanethiols (HS- $\left(\mathrm{CH}_{2}\right)_{11^{-}}$ $\mathrm{OH})$ adsorbed on $\mathrm{Au}$ films $(\mathrm{Au}-\mathrm{OH})$ induce highly-controlled oriented nucleation of calcite crystals from the (104) crystallographic plane. ${ }^{30,34}$ The formation of (104)-oriented calcite occurred, when the template was kept in a crystallizing solution for more than 2 hours. We have noticed that prior to nucleating the oriented calcite crystals, the $\mathrm{Au}-\mathrm{OH}$ templates bear spherulitic particles with diameters of 0.5-1.0 $\mu \mathrm{m}$ (Fig. 1a,b). These particles were confirmed by IR and XRD to be composed of ACC. By systematically removing the substrates at different time intervals from the crystallizing solution, we observed the formation of ACC as well as its transition to oriented calcite crystals. When left in the crystallizing solution, ACC particles slowly transformed into (104)-oriented calcite crystals. The crystals grew at the expense of the amorphous phase, leaving behind a depletion halo in the consumed ACC film (Fig. 1c). When the Au-OH templates bearing spherical ACC deposits were removed from the solution before crystallization and then kept in a dry atmosphere, ACC was stabilized and did not transform into calcite. The ability of hydroxyl-terminated SAMs to stabilize ACC without any additives is remarkable and is reminiscent of the stabilizing activity of threonine- and serine-rich proteins isolated from biogenic ACC. 4,13

When exposed to humid environment, ACC particles slowly start to self-dissolve, flatten, spread, fuse and crystallize into a (104)-oriented calcitic film (Fig. 1d). In this work we explore the ability to govern the recrystallization process, so that instead of the uncontrolled transition of the ACC particles on the Au-OH surface into the (104)-oriented calcite, the crystallization can be now triggered on demand and the growth of crystals in various, highly-controlled orientations could be achieved. To realize this goal, we fabricated a secondary SAM template that had a high calcite-nucleating capability. We have reported earlier that carboxylic acid-terminated SAMs supported on gold are very active in inducing the nucleation of calcite. ${ }^{14,30,33,35}$ Moreover, oriented crystal growth occurs, and the crystals are oriented with the $(01 l)$ nucleating plane $(l=$ 2-5) when grown on the SAM of HS- $\left(\mathrm{CH}_{2}\right)_{15}-\mathrm{COOH}$ and with the (113) nucleating plane when grown on the SAM of HS- $\left(\mathrm{CH}_{2}\right)_{10}-\mathrm{COOH}^{35}$ The secondary templates bearing $\mathrm{COOH}-$ terminated SAMs $\left(\mathrm{Au}-\mathrm{C}_{\mathrm{n}}-\mathrm{COOH}\right)$ were brought in direct contact with the primary Au-OH template covered with the ACC (Fig. 2a). The crystallization was initiated by introducing $\mathrm{H}_{2} \mathrm{O}$ to the system at ambient temperature and pressure. Within $15 \mathrm{~min}$ of introducing a droplet of $\mathrm{H}_{2} \mathrm{O}$, the transformation of ACC to calcite crystals was complete as observed by optical and scanning electron microscopy. The crystals grew on the secondary template by consuming the ACC reservoir. The secondary template played a critical role in inducing the recrystallization process as well as in controlling the orientation and the shapes of the transformed calcite crystals. Calcite crystals nucleated from the (012) plane were formed on the $\mathrm{Au}-\mathrm{C}_{15}-\mathrm{COOH}$ template (Fig. $2 \mathrm{~b}$ ) and calcite crystals nucleated from the (113) plane were formed on the $\mathrm{Au}-\mathrm{C}_{10}-\mathrm{COOH}$

\footnotetext{
${ }^{34}$ Aizenberg, J.; Black, A. J.; Whitesides, G. M. Nature 1999, 398, 495.

${ }^{35}$ Han, Y.-J., Aizenberg, J. Angew. Chem. Int. Ed., 2003, 42, 3668.
} 
template (Fig. 2c). When non-nucleating surface, such as methyl-terminated SAM (HS- $\left(\mathrm{CH}_{2}\right)_{11^{-}}$ $\mathrm{CH}_{3}$ on $\mathrm{Au}$ ) was used as the secondary template, no recrystallization occurred.

Our results show that by separating the template for the ACC deposition from the nucleating template, we were able to store the amorphous phase until needed, and use it as an ions reservoir for the recrystallization process when the crystallization is desired. It is important to emphasize again that the transformation of ACC to calcite occurs in the absence of any additional calcium and carbonate ions. It is hypothesized that the recrystallization process only requires a very small amount of $\mathrm{H}_{2} \mathrm{O}$ to dissolve the very soluble ACC particles within the confined space near the secondary surfaces. The presence of the appropriate functional groups (e.g. carboxylic acid) on the secondary surfaces in a near proximity to the dissolving ACC particles is essential for changing the energy landscape in the system; in other words, for concentrating the dissolved ions to reach high supersaturation levels and providing nucleation sites for oriented calcite crystallization. Currently, experiments to convert ACC particles to calcite crystals in the presence of a secondary nucleating template by controlling the humidity level are underway.

In addition to inducing oriented nucleation on demand, we can control the precise location and pattern of crystallization. For example, we used microcontact printing to form various patterns of carboxylic acid-terminated spots in the methyl-terminated background on the secondary template. ${ }^{34,36}$ When such micropatterned template was brought in contact with the ACC, the crystal growth occurred only at the patterned locations (Fig. 3a). For example, Figure $3 \mathrm{~b}$ shows a square array of oriented calcite crystals formed on a secondary surface. Interestingly, a negative pattern of the ACC particles remained on the Au-OH template (Fig. 3c). As described above, these ACC particles, if kept in a humid environment, spread, fuse and crystallize into a (104)-oriented calcitic film over time; however, with this approach a micropatterned film is created. Our strategy makes it possible, therefore, to template both crystalline and amorphous micropatterned structures.

It has also been shown previously that ACC synthetic and biogenic particles can be formed in the presence of dopants such as $\mathrm{Mg}^{2+}$ ions and organic molecules (e.g. peptides, polymers). ${ }^{17,19-26}$ This led us to believe that ACC might be potentially used as a general storage medium for various foreign molecules along with calcium and carbonate ions (Fig. 4a). In order to confirm this hypothesis, experiments were carried out to produce several batches of ACC spherulites with varying amounts of dopants incorporated in their structures. $\mathrm{Mg}^{2+}$ ions were used as the initial dopant, since $\mathrm{Mg}$ ions are often associated with biogenic calcium carbonates and the effect of $\mathrm{Mg}$ on the formation of synthetic ACC has been extensively studied. ${ }^{17,19,20}$ Spherulitic ACC particles with different concentrations of $\mathrm{Mg}^{2+}$ ions were synthesized by adding varying concentrations of $\mathrm{Mg}^{2+}$ to the calcium chloride solution $(\mathrm{Mg} / \mathrm{Ca}=0-5)$. The resulting ACC spherulites formed on the surfaces of $\mathrm{Au}-\mathrm{OH}$ templates showed spherical morphologies identical to those synthesized in the absence of $\mathrm{Mg}^{2+}$ ions. The incorporation of $\mathrm{Mg}^{2+}$ ions to the ACC spherulites was confirmed by EDAX measurements. The transformation of ACC doped with $\mathrm{Mg}^{2+}$ to calcite crystals was performed as described for the undoped case. Calcite crystals formed on the secondary template showed modified morphologies, compared to a regular calcite rhombohedron. The morphological changes were consistent with the modified morphologies reported earlier for calcite crystals grown from solution by the supersaturation methods with $\mathrm{Mg}^{2+}$ ions. ${ }^{33,37}$ In particular, the growth of calcite crystals in the $a, b$-plane was hindered by the

\footnotetext{
${ }^{36}$ Aizenberg, J. Adv. Mater., 2004, 16, 1295.

${ }^{37}$ Albeck, S.; Aizenberg, J.; Addadi, L.; Weiner, S. J. Am. Chem. Soc. 1993, 115, 11691.
} 
presence of $\mathrm{Mg}^{2+}$ ions, resulting in the anisotropic elongation of the crystals in the c-axis direction (Fig. 4b). We have shown that the extent to which the morphological change takes place depends on the concentration of $\mathrm{Mg}^{2+}$ ions in the solution. ${ }^{33}$ Similarly, the newlytransformed calcite crystals on the HS- $\left(\mathrm{CH}_{2}\right)_{10}-\mathrm{COOH}$ functionalized secondary template were affected by $\mathrm{Mg}^{2+}$ ions in a varying degree depending on the concentration of $\mathrm{Mg}$ ions incorporated within the ACC spherulites (Fig. 4b). Interestingly, when the incorporation of $\mathrm{Mg}^{2+}$ ions into the ACC particles was greater than $\sim 10 \mathrm{~mol} \%$, only ultra-stable ACC particles formed, which did not transform to calcite crystals even when the secondary surface was introduced. This may be a pathway for biological species to control the formation of soluble (temporary) and permanent biogenic ACC structures.

We have also studied the ability to store various organic molecules in ACC and their incorporation into the recrystallized calcite. For example, L-aspartic acid (L-Asp) and fluorescent dyes were chosen as the dopants. Similar to the results observed for $\mathrm{Mg}^{2+}$-doped ACC, various concentrations of L-Asp or dyes can be introduced to synthetic ACC. The transformation of ACC to calcite by contacting the secondary nucleating template resulted in the formation of organics-doped calcite crystals (Fig. 4c).

These results clearly demonstrate that inorganic or organic dopants can be stored in the ACC spherulites in various concentrations. These doped ACC spherulites can then function as reservoirs for ions other than calcium and carbonate, which would affect the crystallizing behavior of the resulting crystals and be incorporated into their structure. We can speculate that similar phenomenon might be relevant to naturally occurring ACC in biological species. It is conceivable that during the formation of biogenic ACC, organisms may deposit additional metal ions and/or organic molecules within the phase. Then, when a need arises to construct crystalline calcium carbonates with specific morphology, orientation and strength, the incorporated molecules co-dissolve along with calcium carbonates from the composite ACC and contribute to the formation of crystalline material by controlling their morphologies, sizes, shapes, impurity content and defect distribution.

In conclusion, a successful synthesis of stable synthetic ACC with and without additives was achieved by using a hydroxyl-terminated SAM as the template for calcium carbonate precipitation. We show that the stabilized ACC can be utilized as a precursor phase for the recrystallization into calcite. Crystallization can be triggered on command when desired, by introducing a secondary template engineered with appropriate active functional groups to induce nucleation. Foreign molecules and ions can be doped into synthetic ACC particles, and further participate in the recrystallization process and accumulate in the newly-formed crystals. This approach makes it possible to control the timing of the recrystallization process, the orientation of the crystals, their doping, morphology and micro/nanopattern of crystallization. The advantage of this system is that ACC can be indefinitely used as a storage of ions, and the highly-controlled crystallization process commences on command upon contacting an appropriate nucleating template, conceivably similar to the mechanism of amorphous-tocrystalline transition occurring in nature.

This work performed under the auspices of the U.S. Department of Energy by Lawrence Livermore National Laboratory under Contract DE-AC52-07NA27344. 
a
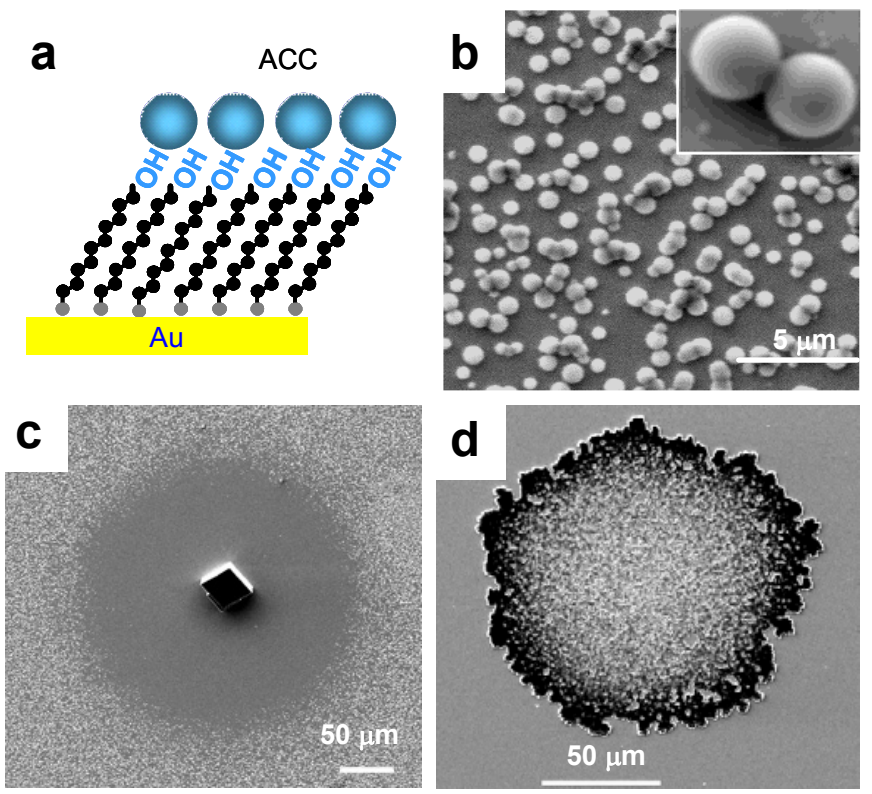

Figure 1. Stabilization of amorphous calcium carbonate on a hydroxyl-terminated template. (a) Schematic illustration of the ACC formation on a Au-OH SAM. (b) SEM of the ACC spheres removed from the solution after $45 \mathrm{~min}$. Inset shows a high-magnification image. (c) SEM of the Au-OH template removed from the solution after $1.5 \mathrm{hrs}$. Recrystallization of ACC into a (104)-oriented calcite crystal occurs. (d) When exposed to a humid atmosphere, ACC spheres on a Au-OH template flatten, spread, fuse and form a continuous film that slowly crystallizes. 


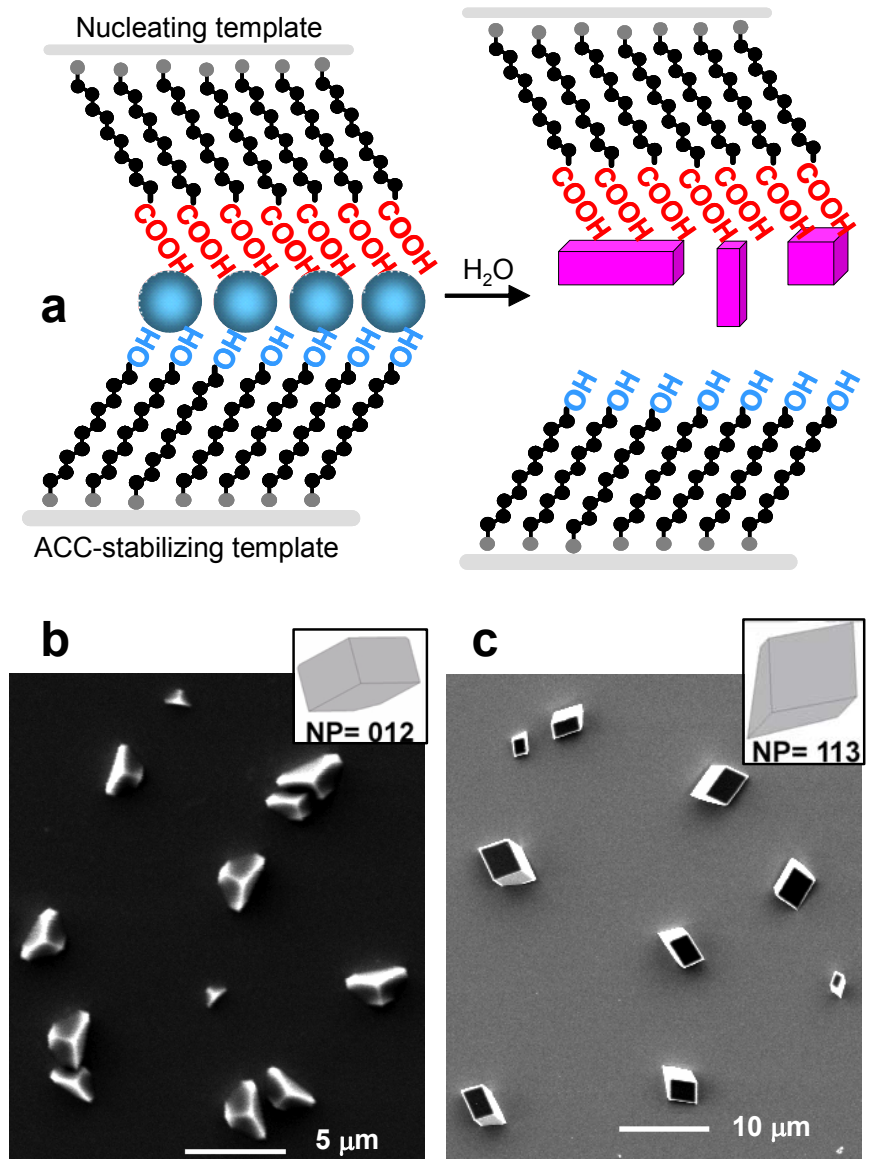

Figure 2. Recrystallization of the ACC stored on the primary $\mathrm{Au}-\mathrm{OH}$ template when brought in contact with a secondary template functionalized with calcite nucleation sites. (a) Schematic presentation of the process. (b) SEM of the oriented calcite crystals formed on a secondary nucleating template of $\mathrm{Au}-\mathrm{C}_{15}-\mathrm{COOH}$. Oriented nucleation from the calcite (012) plane induced by the $\mathrm{Au}-\mathrm{C}_{15}-\mathrm{COOH}$ template ${ }^{30,35}$ takes place. Inset shows a computer simulation of the crystal nucleated from the (012) nucleation plane (NP). (c) SEM of the oriented calcite crystals formed on a secondary nucleating template of $\mathrm{Au}-\mathrm{C}_{10}-\mathrm{COOH}$. Oriented nucleation from the calcite (113) plane induced by the $\mathrm{Au}-\mathrm{C}_{10}-\mathrm{COOH}$ template ${ }^{35}$ takes place. Inset shows a computer simulation of the crystal nucleated from the (113) NP. 

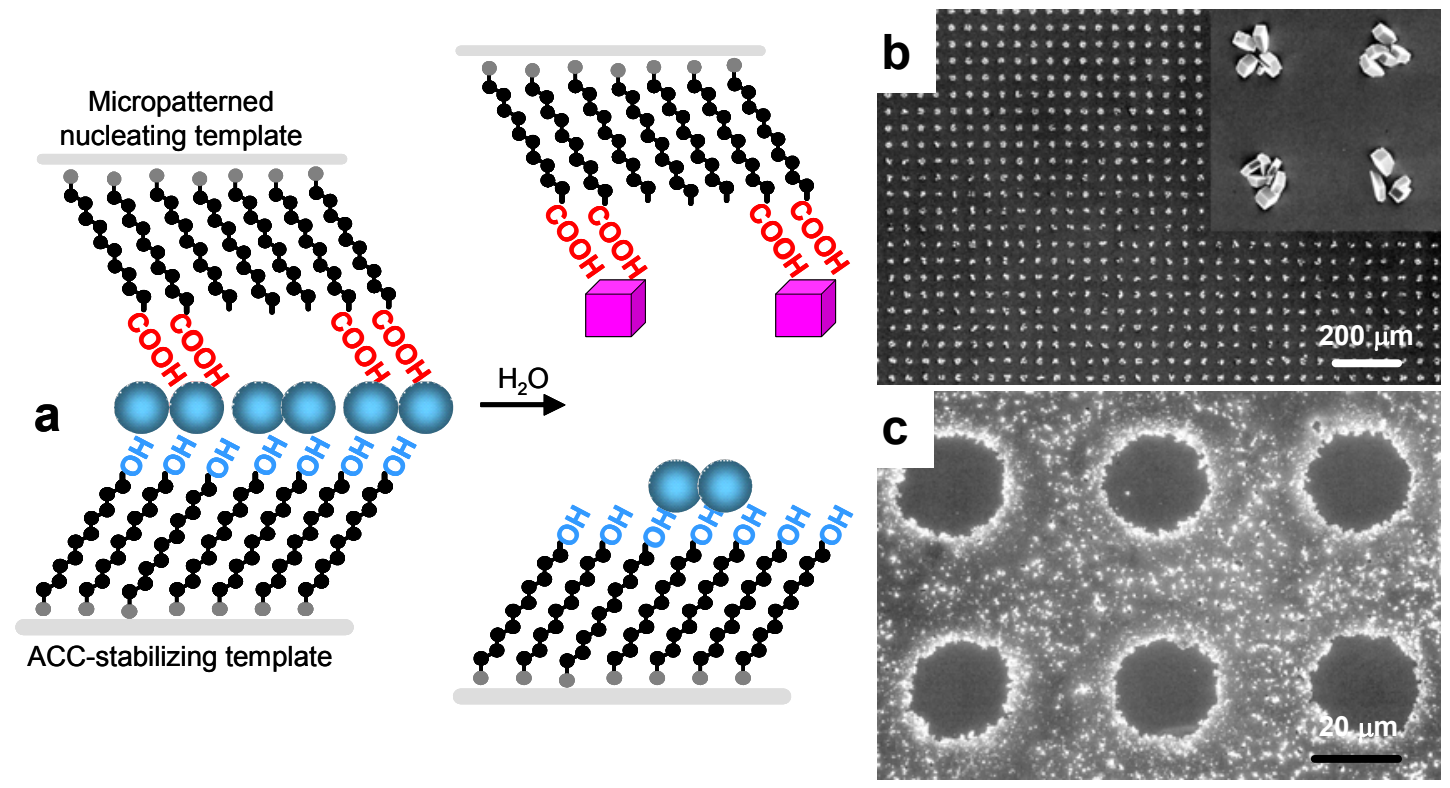

Figure 3. Recrystallization of the stored ACC film into a micropatterned crystalline array upon contacting a secondary template decorated with a pattern of nucleating sites. (a) Schematic presentation of the process. (b) Highly regular square array of (012)-oriented calcite crystals formed on a secondary template, on which a pattern of $10-\mu \mathrm{m}$ circles of HS- $\left(\mathrm{CH}_{2}\right)_{15}-\mathrm{COOH}$ SAM was formed in the HS- $\left(\mathrm{CH}_{2}\right)_{11}-\mathrm{CH}_{3}$ backround by microcontact printing. (c) Consumption and removal of ACC particles occurs locally from the spots contacting the nucleating $\mathrm{COOH}$ regions. As a result, a pattern opposite to the one formed on the secondary nucleating template is left on the ACC film. 


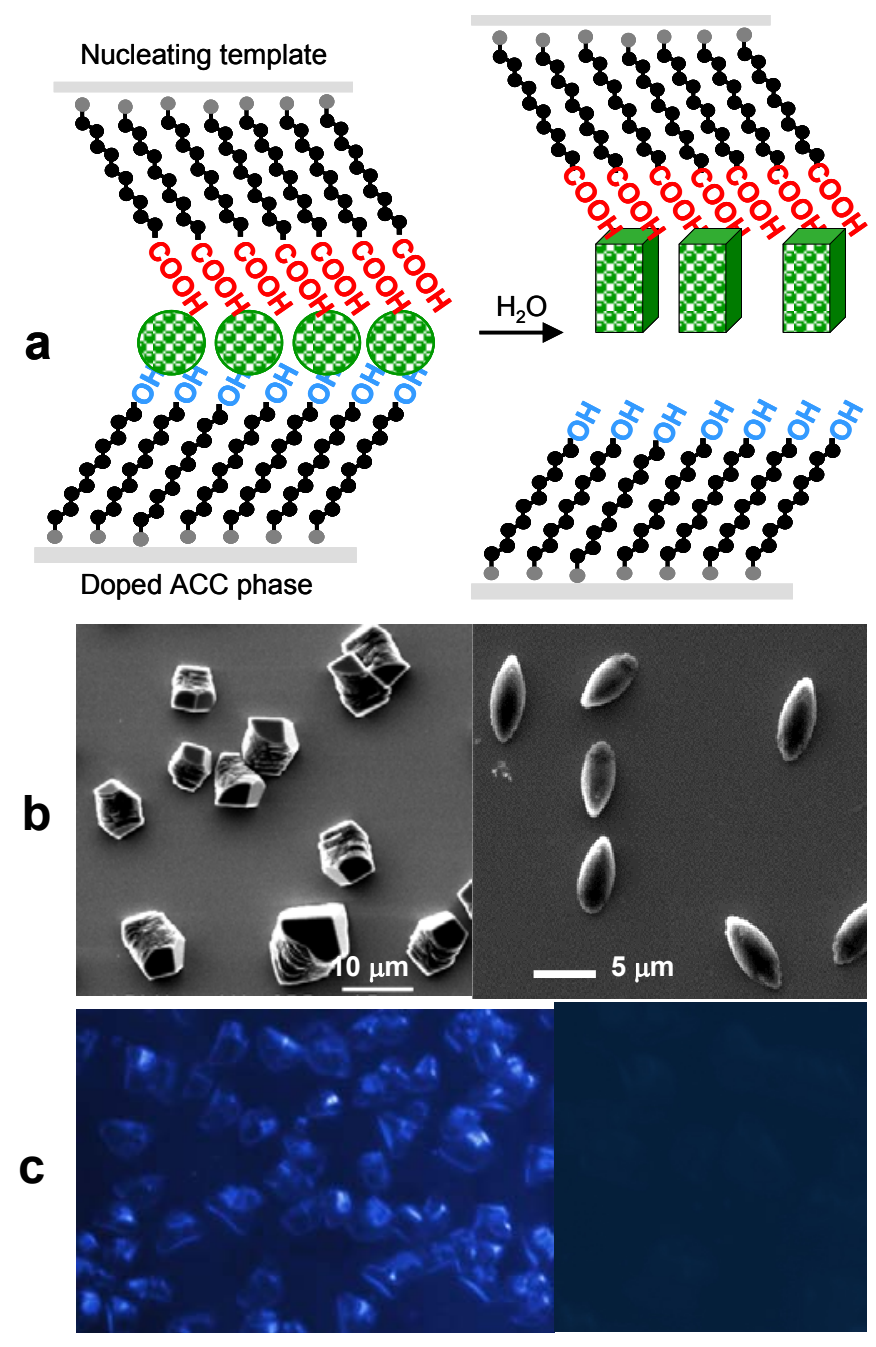

Figure 4. ACC particles can be used as a general storage medium for foreign ions and macromolecules that affect the growth and composition of recrystallized calcite. (a) Schematic presentation of the process. (b) SEM of calcite crystals recrystallized on a $\mathrm{Au}-\mathrm{C}_{10}-\mathrm{COOH}$ template from the $\mathrm{ACC}$ phase doped with $\mathrm{Mg}$ ions. $\mathrm{Mg}$ is incorporated into the crystals and induces a typical morphological modification. The extent, to which the crystals are affected, depends on the doping level: $\mathrm{Mg} / \mathrm{Ca}=1$ (left). $\mathrm{Mg} / \mathrm{Ca}=2$ (right). (c) (c) Left: Fluorescent light micrograph of calcite crystals recrystallized on a $\mathrm{Au}-\mathrm{C}_{15}-\mathrm{COOH}$ template from the ACC phase doped with a fluorescent dye. The dye is clearly incorporated into the crystals. Right: Control experiment with no dye. 